\title{
ChemComm
}

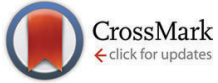

Cite this: Chem. Commun., 2016, 52,12199

Received 5th September 2016, Accepted 17th September 2016

DOI: $10.1039 / c 6 c c 07240 b$

www.rsc.org/chemcomm

\section{Revealing the remarkable structural diversity of the alkali metal transfer agents of the trans-calix[2]benzene[2] pyrrolide ligand $\dagger$}

\author{
M. Ángeles Fuentes, Antonio J. Martínez-Martínez, Alan R. Kennedy and \\ Robert E. Mulvey*
}

\begin{abstract}
Excellent reagents for transferring their heterocalix[4]arene ligand to f-block organometallic complexes, lithium, sodium and potassium trans-calix[2]benzene[2]pyrrolides have been found to adopt a fascinating series of structures in their own right.
\end{abstract}

Whilst following the recent seminal breakthroughs in f-block elements literature, ${ }^{1}$ the contributions of trans-calix[2] benzene[2]pyrrole, $\mathrm{H}_{2} \mathrm{~L}^{\mathrm{Ar}}$, in its doubly deprotonated ligand form $\left(\mathrm{L}^{\mathrm{Ar}}\right)^{2-}$, caught our eye. Introduced by Sessler et al. ${ }^{2}$ as one of a series of heterocalix[4]arene hybrids, $\left(\mathrm{L}^{\mathrm{Ar}}\right)^{2-}$ is made up of four aromatic rings of alternate pyrrolide and arene units that connect via dimethylmethane linkers. Possessing interrupted conjugation, the ligand is blessed with conformational and coordinative flexibility that renders it effective at supporting a range of organometallic lanthanide and actinide complexes. These include uranium(III and IV), samarium(III) and thorium(Iv) complexes and most recently organoneptunium(III) complexes. ${ }^{1}$ Characterisation of these complexes especially via single crystal X-ray crystallography, a particularly noteworthy feat for the technologically challenging radiotoxic organoneptunium(III) complexes, have uncovered an assortment of trans-calix[2]benzene[2]pyrrolide $\sigma$ and $\pi$ bonding modes, typically mono or bis( $\left(\kappa^{1}\right.$-areneide) coordinations, bis( $\kappa^{1}$-pyrrolyl) coordination, bis $\left(\eta^{5}\right.$-pyrrolyl) sandwiching and $\operatorname{bis}\left(\eta^{6}\right.$-arene $)$ sandwiching.

Alkali metal reagents play an important if somewhat understated role in this emerging organometallic chemistry of f-block elements. For example, potassium intermediate $\mathrm{K}_{2}\left(\mathrm{~L}^{\mathrm{Ar}}\right)$ reacted with $\mathrm{SmCl}_{3}(\text { thf })_{3}$ to generate the corresponding $\mathrm{Sm}^{\mathrm{III}} \mathrm{Cl}\left(\mathrm{L}^{\mathrm{Ar}}\right)$, where $\mathrm{L}$ adopts a $\sigma, \pi$ bonding mode with the pyrrolide $\mathrm{N}$ atoms $\sigma$-bonded to $\mathrm{Sm}$, which occupies a bis $\left(\eta^{6}\right.$-arene) $\pi$-pocket. Lithium intermediate, $\mathrm{Li}_{2}\left(\mathrm{~L}^{\mathrm{Ar}}\right)$, made by reaction of $\mathrm{H}_{2} \mathrm{~L}^{\mathrm{Ar}}$ with LiHMDS $^{3}$ [HMDS $=1,1,1,3,3,3$-hexamethyldisilazide; also known

WestCHEM, Department of Pure and Applied Chemistry, University of Strathclyde, Glasgow, G1 1XL, UK. E-mail: r.e.mulvey@strath.ac.uk

$\dagger$ Electronic supplementary information (ESI) available: General procedures, crystal structure determinations, syntheses and NMR spectroscopic data. CCDC 1499377-1499382. For ESI and crystallographic data in CIF or other electronic format see DOI: $10.1039 / \mathrm{c} 6 \mathrm{cc} 07240 \mathrm{~b}$ as bis(trimethylsilyl)amide] in toluene solution, was used to convert $\mathrm{UI}_{3}$ to dinuclear $\mathrm{U}_{2}^{\mathrm{III}} \mathrm{I}_{4}\left(\mathrm{~L}^{\mathrm{An}}\right)$, with one $\mathrm{U}$ in a bis $\left(\eta^{5}\right.$-pyrrolyl $)$ pocket and the second $\mathrm{U}$ in a bis $\left(\eta^{6}\right.$-arene) pocket. ${ }^{1 b}$ Moreover, alkali metals can be incorporated into actinide products as seen in $\left.\mathrm{K}\left[\mathrm{Th}\left\{\mathrm{N}\left(\mathrm{SiMe}_{3}\right)_{2}\right\}\left(\mathrm{L}^{\mathrm{Ar}}\right)\right]\right]^{1 b}$ synthesised by reaction of $\mathrm{Th}^{\mathrm{TV}} \mathrm{Cl}_{2}\left(\mathrm{~L}^{\mathrm{Ar}}\right)$ with excess KHMDS. Here, aside from substituting $\mathrm{Cl}$ ligands by the silylamide, the $\mathrm{K}$ occupies the bis(arene) pocket of the macrocycle but interestingly also facilitates double $\mathrm{C}-\mathrm{H}$ metallation of the $\mathrm{L}$ aryl groups by the $\mathrm{Th}^{\mathrm{IV}}$ centre.

Recently, theoretical investigations by Schreckenbach, Pan et al. ${ }^{4}$ have put the alkali metal ( $\mathrm{Li}, \mathrm{Na}$ and $\mathrm{K}$ ) derivatives of the trans-calix[2]benzene[2]pyrrolide ligand in the spotlight for accessing low-valent uranium and transuranium complexes. Surprisingly, these important alkali metal intermediates $\mathrm{AM}_{2}\left(\mathrm{~L}^{\mathrm{Ar}}\right)$ have not been studied in their own right. Knowing that the structures of alkali metal compounds can have a profound influence on the outcome of reactions, ${ }^{5}$ we set out this study to isolate and characterize these intermediates and where possible to resolve their structures. As outlined here, the results obtained for the congeneric series of $\mathrm{AM}=\mathrm{Li}, \mathrm{Na}, \mathrm{K}$ are remarkable.

In previous work potassium and lithium derivatives of transcalix[2]benzene[2]pyrrole were generated in situ by treating the free ligand with potassium hydride ${ }^{1 a}$ or lithium HMDS $^{1 b}$ respectively. Adapting this procedure, a set of the alkali metal macrocycles was accessed by reaction of the free ligand with an appropriate metallating agent, namely either $n \mathrm{BuLi}$, NaHMDS or KHMDS (Scheme 1). Crystallisation of the solvated potassium complex $\left[\mathrm{K}_{2}\left(\mathrm{~L}^{\mathrm{AI}}\right)(\text { thf })_{3}\right], \mathbf{1}$, was accomplished in neat thf solution. Initially obtained as a white solid, crystals of $\left[\mathrm{Li}_{2}\left(\mathrm{~L}^{\mathrm{Ar}}\right)(\mathrm{thf})_{4}\right], 2$, suitable for X-ray analysis, were secured via slow diffusion of $n$-hexane into a tetrahydrofuran solution of 2. The distinction between thf-rich $\left[\mathrm{Na}_{2}\left(\mathrm{~L}^{\mathrm{Ar}}\right)(\mathrm{thf})_{3}\right], 3$ and its thf-poor variant $\left[\left\{\mathrm{Na}_{2}\left(\mathrm{~L}^{\mathrm{Ar}}\right)(\operatorname{thf})_{2}\right\}\left\{\mathrm{Na}_{2}\left(\mathrm{~L}^{\mathrm{Ar}}\right)\right\}\right]_{\infty}, 4$ came about by diffusing $n$-hexane into a tetrahydrofuran solution of the latter but growing the former from an all thf solution; ${ }^{6}$ while thf-free $\left[\mathrm{Na}_{2}\left(\mathrm{~L}^{\mathrm{Ar}}\right)\right]_{4}, \mathbf{5}$ was obtained by performing the sodiation reaction in neat methylcyclohexane.

As has been shown in papers, intuitively one would be inclined to (chem)draw the structure of the potassium intermediate with 


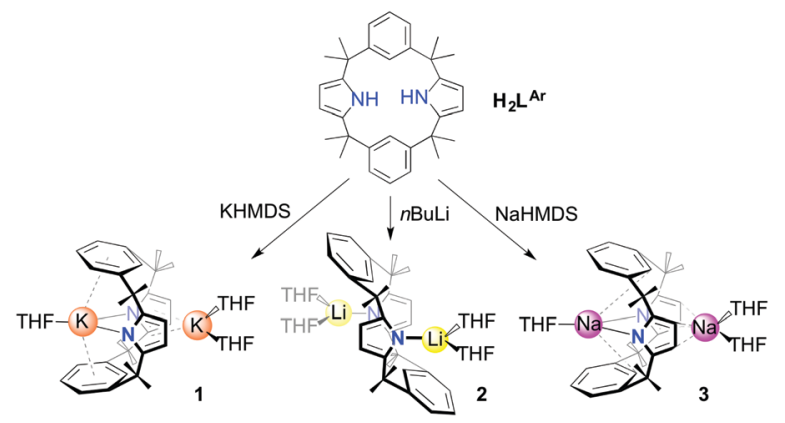

Scheme 1 Synthesis and monomeric structures of alkali metal transcalix[2]benzene[2]pyrrolide complexes, 1-3.

symmetry equivalent $\mathrm{K}$ cations attached to $\mathrm{N}$ atoms (i.e., replacing the two $\mathrm{NH}$ in $\mathrm{H}_{2} \mathrm{~L}^{\mathrm{Ar}}$ by two NK in Scheme 1). Surprisingly, this representation of thf-rich $\mathbf{1}$ is found to be inappropriate. In actuality, the $\mathrm{K} 1$ cation bridges the two $\mathrm{N}$ atoms with one thf in a $\sigma$-bonded $\mathrm{N}_{2} \mathrm{O}$ pseudo-equatorial plane, while occupying a sandwich position between the two axially disposed $\kappa^{1}-\pi$-bonded aryl rings (Fig. 1a). On the other hand, K2 occupies the bis $\left(\eta^{5}\right.$-pyrrolide) pocket with its coordination completed by two thf ligands. An assessment of bond lengths emphasizes this bonding distinction (mean K1-N, $2.88 \AA$ A; mean $\mathrm{K} 2-\mathrm{N} 3.20 \AA$ ). In fact, reflecting the distinct coordination mode for $\mathrm{K} 1 v s$. K2, 1 could be seen as a rare example of a potassium potassiate, ${ }^{7}$ where $\mathrm{K} 1$ represents the ate moiety in strongly binding to the two anionic pyrrolyl groups through their $\mathrm{N}$ atoms, $\mathrm{K} 1 \mathrm{~N}_{2}$, whilst $\mathrm{K} 2$ is surrounded by all neutral donors (thf ligands and the $\pi$-system of the $\eta^{5}$-pyrrolide) if disregarding the long, weak contacts with the pyrrolyl $\mathrm{N}$ atoms. This is the first time that $\mathrm{K}$ has been found in the bis $\left(\eta^{5}\right.$-pyrrolide $)$ pocket, drawing comparisons with the coordination of $\mathrm{Np}(\mathrm{III})$ in $\left[\mathrm{K}(\mathrm{DME})_{n}\left\{\left(\mathrm{~L}^{\mathrm{Ar}-\mathrm{H}}\right) \mathrm{Np}^{\mathrm{III}}\left(\mathrm{OCH}_{3}\right)\right\}\right]_{2}$

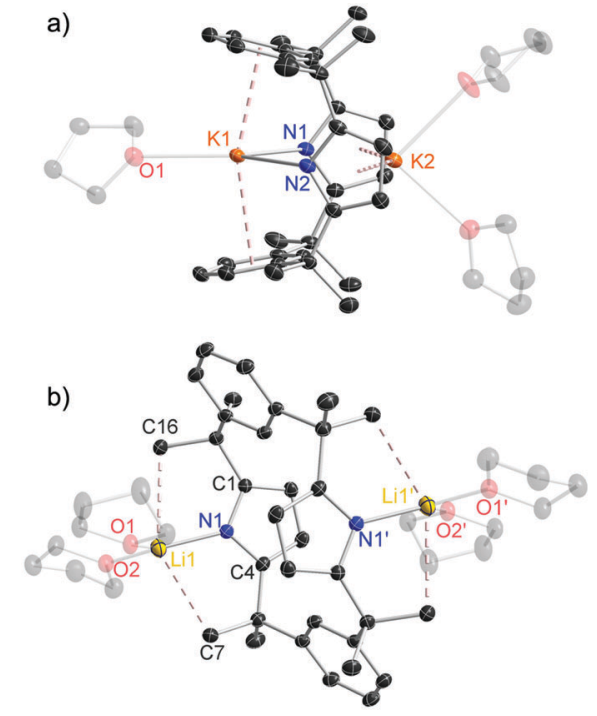

Fig. 1 Molecular structures of (a) $\left[\mathrm{K}_{2}\left(\mathrm{~L}^{\mathrm{Ar}}\right)(\mathrm{thf})_{3}\right], \mathbf{1}$, and (b) $\left[\mathrm{Li}_{2}\left(\mathrm{~L}^{\mathrm{Ar}}\right)(\mathrm{thf})_{4}\right], 2$ Thermal ellipsoids are displayed at $35 \%$ probability. Hydrogen atoms and one disordered component of two thf ligands for 1 have been omitted for clarity. The dashed lines illustrate the K...C and Li. . Me contacts for 1 and $\mathbf{2}$, respectively. For $\mathbf{2}$, the symmetry operation used to generate equivalent atoms denoted with' is $-x+2,-y+1,-z+1$. where the two thf ligations in $\mathbf{1}$ match the actinide ion's engagement with two MeO bridges though $\mathrm{Np}$ (III) also displays an additional interaction with a deprotonated aryl ring. ${ }^{1 d}$

Though molecular like 1, the structure of the smaller lithium congener $\left[\mathrm{Li}_{2}\left(\mathrm{~L}^{\mathrm{Ar}}\right)(\text { thf })_{4}\right], 2$ (Fig. 1b), differs significantly. Within its centrosymmetric arrangement, the bis( $\pi$-benzene) pocket lies empty. The Li cations cling to the outside of the macrocycle through a $\sigma$-bonded $\mathrm{N}$ atom [Li1-N1, 1.940(3) $\AA$ ] . This $\mathrm{N}$ atom displays a distorted planar geometry (sum of bond angles, $358.49^{\circ}$ ) with distortion pronounced inside the pyrrolyl ring [C4NC1 bond angle, $\left.105.68(12)^{\circ}\right]$. Structures of this type in which one or more pyrrole units has a $\mathrm{N}$ atom at the macrocycle exterior have been labelled as $\mathrm{N}$-confused ${ }^{8}$ isomers as in the samarium complex $\left[(\mathrm{L}) \mathrm{Sm}\left(\mathrm{HL}^{\prime}\right)\right]{ }^{1 a}$ where the protonated macrocycle $\mathrm{HL}^{\prime}$ has one exterior $\mathrm{N}$ atom bound to $\mathrm{Sm}$. Completed by two thf ligands, the primary $\mathrm{Li}(\mathrm{N} \times 1 ; \mathrm{O} \times 2)$ coordination sphere in 2 is essentially planar (sum of bond angles, $359.62^{\circ}$ ), though there are two exceedingly long interactions with $\mathrm{C}(\mathrm{Me})$ atoms of the dimethylmethane linkers [Li1-C7, 2.727(3); Li1-C16, 2.815(3) ̊]].

Turning to the intermediate-sized alkali metal sodium, we crystallised the tris(thf) solvate $\left[\mathrm{Na}_{2}\left(\mathrm{~L}^{\mathrm{Ar}}\right)(\text { thf })_{3}\right], 3$, which bears a resemblance to the tris(thf) solvated potassium congener $\mathbf{1}$. The main distinction is that the smaller size of sodium leads to reduced hapticities of the bis(benzene) and bis(pyrrole) rings with its two distinct Na centres, the former being $\eta^{1}$ bound [Na1-C9 2.8254(17); Na1-C25 2.8509(16)] and the latter being $\eta^{2}$ bound [Na2-C2 2.756(2); Na2-C18 2.8443(18); Na2-C19 2.8653(18); $\mathrm{Na} 2-\mathrm{C} 3$ 2.8954(19)] (see ESI $\dagger$ for full details). Interestingly, as alluded to earlier $\left.\left[\left\{\mathrm{Na}_{2}\left(\mathrm{~L}^{\mathrm{Ar}}\right)(\mathrm{thf})_{2}\right\} \mathrm{Na}_{2}\left(\mathrm{~L}^{\mathrm{Ar}}\right)\right\}\right]_{\infty}, \mathbf{4}$, a thf-poor variant was also crystallised. Its zigzag polymeric structural arrangement exhibits four distinct sodium centres (Fig. 2a). Unfortunately, disorder affecting the Na1 and Na4 metal centres hampers the discussion of its structural parameters in detail. It can be said that the Na1 and Na3 centres occupy pockets of the intramolecular bis(benzene) type whilst the Na2 and Na4 centres make intermolecular $\mathrm{Na}$ bis(pyrrole) units that bridge between ligands. A similar $\mathrm{K}$ coordination environment to that of the $\mathrm{Na}$ metal centres in $\mathbf{4}$ is also found in the potassium calix[4]pyrrolide complex $\left[\left\{\mathrm{K}_{3}\left(\text { calix }[4] \text { pyrrolide }{ }^{-3 H}\right)(\text { thf })(\text { toluene })_{2}\right\}\right]_{\infty} \cdot{ }^{9}$

Having crystallised variations of the sodium macrocycle containing different amounts of coordinated thf, we pondered whether crystals of the thf-free version could be obtained. This was achieved by performing the dideprotonative metallation reaction in a methylcyclohexane medium. An X-ray crystallographic determination revealed a remarkably eyecatching tetrameric, octanuclear structure $\left[\mathrm{Na}_{2}\left(\mathrm{~L}^{\mathrm{Ar}}\right)\right]_{4}, \mathbf{5}$ (Fig. 2b). As highlighted in Fig. 2b, a 16-atom $(\mathrm{NaN})_{8}$ ring runs through the structure. Measuring from $\mathrm{H}$ nuclei to $\mathrm{H}$ nuclei the "hole" in the ring is approximately $125 \AA^{3}$, but given the van der Waals radii of an $\mathrm{H}$ approaches $1 \AA$ that reduces the hole size to about $27 \AA^{3}$, approximately the size of a water molecule. There are four crystallographically distinct $\mathrm{Na}$ centres, which fall into two distinct types. Na1 and Na3 occupy the bis $\left(\eta^{6}\right.$-benzene) pocket and form bonds of predominate $\sigma$ character to the pyrrolyl $\mathrm{N}$ atoms as reflected by their short lengths (mean Na-N, $2.40 \AA$ ); whereas $\mathrm{Na} 2$ and Na4 occupy the bridging bis $\left(\eta^{5}\right.$-pyrrolyl $)$ units with a corresponding mean $\mathrm{Na}-\mathrm{N}$ length 
a)

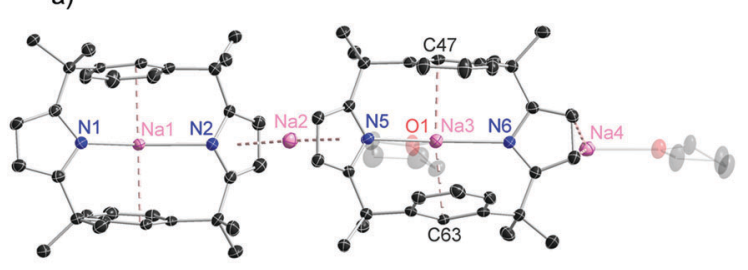

b)

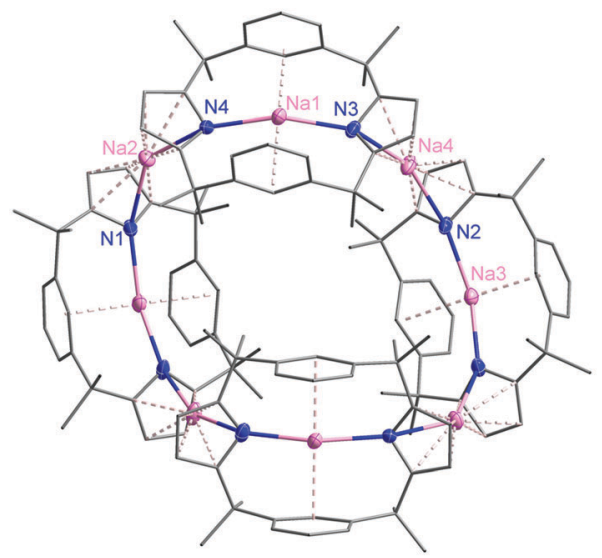

Fig. 2 (a) Molecular structure of $\left[\left\{\mathrm{Na}_{2}\left(\mathrm{~L}^{\mathrm{Ar}}\right)(\mathrm{thf})_{2}\right\}\left\{\mathrm{Na}_{2}\left(\mathrm{~L}^{\mathrm{Ar}}\right)\right\}\right]_{\infty}, 4$, showing the contents of the asymmetric unit. (b) Molecular structure of $\left[\mathrm{Na}_{2}\left(\mathrm{~L}^{\mathrm{Ar}}\right)\right]_{4}$, 5, showing the extended cyclic three dimensional structural framework. Thermal ellipsoids are displayed at 35\% probability and hydrogen atoms are omitted for brevity. Two disordered molecules of thf of crystallisation and disordered components of a $\mathrm{Na}$-thf moiety and a $\mathrm{Na}$ metal centre for 4, and one disordered component of two $\mathrm{C}\left(\mathrm{CH}_{3}\right)_{2}$ groups for 5 have been omitted for clarity. The dashed lines illustrate the $\mathrm{Na}$... C interactions.

of $2.62 \AA$. The contacts between $\mathrm{Na} 1$ and $\mathrm{Na} 3$ with their respective $\operatorname{bis}\left(\eta^{3}\right.$-arene) cavities are in the range $2.707(2)-$ 2.968(2) A. The chameleonic character of sodium to switch from primarily a $\sigma$-bonded stance to a $\pi$-bonded stance with a $\mathrm{NH}$-deprotonated pyrrole ligand has previously been observed in a series of sodium pyrrolylzincate structures. ${ }^{10}$

In addition, compounds 1-5 were successfully characterised by ${ }^{1} \mathrm{H}$ and ${ }^{13} \mathrm{C}$ NMR spectroscopy either in $\left[\mathrm{D}_{8}\right]$ thf or $\mathrm{C}_{6} \mathrm{D}_{6} /\left[\mathrm{D}_{8}\right]$ thf solutions (see $\mathrm{ESI} \dagger$ for full details). All of them are distinguished by the absence of the pyrrolyl $\mathrm{NH}$ resonance and the presence of corresponding signals for the macrocyclic framework. 2 exhibits a characteristic broad singlet at $7.94 \mathrm{ppm}$ in the ${ }^{1} \mathrm{H}$ NMR spectrum for the aromatic $\mathrm{H}$ flanked by the two the $\mathrm{CMe}_{2}$ groups; whereas this $\mathrm{H}$ resonates as a triplet in the range
6.69-6.93 ppm for $\mathbf{1}$ and 3-5. This situation reflects the distinction between the transoid conformation of the aryl units of the macrocycle in its $\mathrm{Li}$ salt form 2 and the alternative cisoid arrangement in the heavier $\mathrm{K}$ and $\mathrm{Na}$ congeners 1 and 3-5. For all of them, a singlet in the range 5.73-6.08 ppm is found for the pyrrolyl moiety in the ${ }^{1} \mathrm{H}$ NMR spectra.

In conclusion, prior to this work the structures of alkali metal derivatives of the dideprotonated trans-calix[2]benzene[2]pyrrole ligand were concealed since these compounds had only been studied as in situ transfer agents in organometallic lanthanide and actinide chemistry. Here, their isolation and structural characterisation have uncovered a surprisingly diverse range of novel structures from dinuclear monomers, to octanuclear tetramers through to chain polymers.

This work was made possible through generous financial support from the EPSRC (award no. EP/K001183/1) and the Royal Society (Wolfson research merit award to R. E. M.). Experimental data supporting this research are openly available at http://dx. doi.org/10.15129/dbceecc0-96d3-4f75-a7eb-a08eaa77b063.

\section{Notes and references}

1 (a) S. Ilango, B. Vidjayacoumar and S. Gambarotta, Dalton Trans., 2010, 39, 6853-6857; (b) P. L. Arnold, J. H. Farnaby, R. C. White, N. Kaltsoyannis, M. G. Gardiner and J. B. Love, Chem. Sci., 2014, 5, 756-765; (c) P. L. Arnold, J. H. Farnaby, M. G. Gardiner and J. B. Love, Organometallics, 2015, 34, 2114-2117; (d) M. S. Dutkiewicz, J. H. Farnaby, C. Apostolidis, E. Colineau, O. Walter, N. Magnani, M. G. Gardiner, J. B. Love, N. Kaltsoyannis, R. Caciuffo and P. L. Arnold, Nat. Chem., 2016, 8, 797-802.

2 J. L. Sessler, W.-S. Cho, V. Lynch and V. Král, Chem. - Eur. J., 2002, 8, 1134-1143.

3 R. E. Mulvey and S. D. Robertson, Angew. Chem., Int. Ed., 2013, 52, 11470-11487.

4 Z. Bao, H.-B. Zhao, N. Qu, G. Schreckenbach and Q.-J. Pan, Dalton Trans., 2016, DOI: 10.1039/c6dt01930g.

5 (a) E. Carl and D. Stalke, in Lithium Compounds in Organic Synthesis, ed. R. Luisi and V. Capriati, Wiley-VCH Verlag GmbH \& Co. KGaA, Weinheim, Germany, 2014, pp. 1-32; (b) A. J. Martínez-Martínez, A. R. Kennedy, R. E. Mulvey and C. T. O'Hara, Science, 2014, 346, 834-837.

6 Mirroring this situation, a second thf-poor variant of 1 was also obtained by diffusion of $n$-hexane into a thf solution. This complex is included in the ESI $\dagger$ for brevity.

7 W. Clegg, M. R. J. Elsegood, L. Horsburgh, R. E. Mulvey and M. J. Ross, Chem. Ber., 1997, 130, 621-631.

8 (a) T. Dubé, J. Guan, S. Gambarotta and G. P. A. Yap, Chem. - Eur. J., 2001, 7, 374-381; (b) I. Korobkov, S. Gambarotta and G. P. A. Yap, Organometallics, 2001, 20, 2552-2559.

9 G. B. Deacon, M. G. Gardiner, P. C. Junk, J. P. Townley and J. Wang, Organometallics, 2012, 31, 3857-3864.

10 J. A. Garden, A. R. Kennedy, R. E. Mulvey and S. D. Robertson, Chem. Commun., 2012, 48, 5265-5267. 